\title{
Learning Environments
}

\section{Steven Lopes Abrantes Polytechnic Institute of Viseu, Viseu, Portugal}

steven@di.estv.ipv.pt

\author{
Luís Borges Gouveia \\ Faculty of Science and \\ Technology, University \\ Fernando Pessoa, \\ Porto, Portugal
}

\begin{abstract}
This study has two main goals: the first is to validate the perception that students have to the use of applications on mobile devices; and the second is the validation of the perception and potential use of mobile applications for supporting collaborative environments.

Additionally, an analysis of data collected is presented. From this exercise it was possible to define the profile of respondents as people who know a lot of mobile applications in collaborative environments, that they use only the most common and popular ones, and that the majority are not willing to pay to use them. They are also people who use common applications on mobile devices. and those who do not use them want to use them in the future. The majority of respondents have already used forums (in real settings), linking this to good learning.
\end{abstract}

Key Words: M-Learning, Collaborative Learning, Natural Learning, Learning Environments

\section{Introduction}

The changes in the learning process can be related in many ways to technological advances; in particular, learning through Information and Communication Technology (ICT) was the obvious step in the evolution of distance education. E-learning also provides the opportunity to create learning environments focused on students as a global trend to transfer to a centered user focus (instead of a more traditional perspective from the offer, this case, school and teacher oriented). These learning scenarios are characterized by being interactive, efficient, and easily accessible and distributed.

Technological applications and how they are used has evolved in such a way that the manipulation of learning objects is no longer limited to a personal computer, but extended to the use of mobile devices (PDA, mobile phone, Smartphone, Laptops, and Tablet PC). Mobile devices provide a greater range of applications and offer to the education sector the benefits of mobile com-

Material published as part of this publication, either on-line or in print, is copyrighted by the Informing Science Institute. Permission to make digital or paper copy of part or all of these works for personal or classroom use is granted without fee provided that the copies are not made or distributed for profit or commercial advantage AND that copies 1) bear this notice in full and 2) give the full citation on the first page. It is permissible to abstract these works so long as credit is given. To copy in all other cases or to republish or to post on a server or to redistribute to lists requires specific permission and payment of a fee. Contact 0HPublisher@InformingScience.org to request redistribution permission. puting. These results in the establishment of a new area of activity related with the use of technology in learning, named m-learning.

This educational model based on the use of mobile devices has been developed over the past few years, resulting in several research projects and some commercial products. Current and past 
promises of more learning outcomes needed to be evaluated.

\section{Natural Learning Environments for Education}

Since childhood we learn to associate, identify, and categorize objects through the experiences we have with them. A new object or toy attracts the child's attention through, among other factors, color and shape. When the child is in contact with a new object, he takes it, plays with it, tries to break it, and also even tries to taste it, with no exterior interference. The children just try to explore the object, taking their own conclusions. These conclusions are the settings that a child gives to the object. This leads to an experience that will hardly be forgotten. This is, in brief, what is considered as a natural process of learning (Okyere, Rothkopf, \& Kim, 1993).

The natural process of learning has the following phases (Okyere, et al., 1993):

- Observation and implementation;

- Research and manipulation;

- Acceptance and assimilation.

Caine and Caine (2007) defend that natural education is the commitment of perception and action that one has on things. All the real world learning impact changes the way people come to see and interpret things, situations, and themselves, or alternatively changes how people act or think in the world and plan their actions.

Caine and Caine (2007)also refer the existence of four phases to the natural learning process and also note that the key to learning is the phase of Feedback:

- Perception;

- Action;

- Feedback;

- New learning.

A child learns through this natural process; he observes and focuses on an object, plays with it, gets feedback and learns with it. Teenagers, when interacting with their video games, engage, observe, make decisions, act on the basis of their current skills, obtain feedback, and reflect on what they need to change, and this improves their skills and previous knowledge. Their moral values are intrinsically increased based on their actions and feedback obtained throughout the learning process (Caine \& Caine, 2007).

Natural teaching is based on curiosity and the development of projects, where participants share their knowledge to achieve a particular goal. The knowledge shared by participants in a project will vary, depending on the actual project itself and the personality of its participants. The knowledge will be acquired through research, testing, and errors that are made over the development of the project. The ability to seek knowledge, to share knowledge, and to make the right decisions is the main key to achieve the ultimate goal. When you reach a certain specific purpose another one is launched (Webb, 2000).

A natural learning environment is characterized by (Chiarello, et al., 2001):

- A variety of situations where people live, learn and play;

- Natural and comfortable environments;

- Environments where everyone has the chance to participate; 
- Environments where children and families participate in routines and activities that are important to them;

- Patterns of daily living.

People learn in a variety of ways. We can learn like a parrot, which it repeats what he hears, or as apes, where they do what they see. We can also learn more efficiently, in ways that we fortify our own experiences and we can learn using strategies that alters our attitudes and our mode of acting and being (Atkin, 1997).

Holt mentioned by Atkin (1997) describes a model to explain what kind of natural learning that we value and what is the natural learning that is appropriate in a given context (Figure 1).

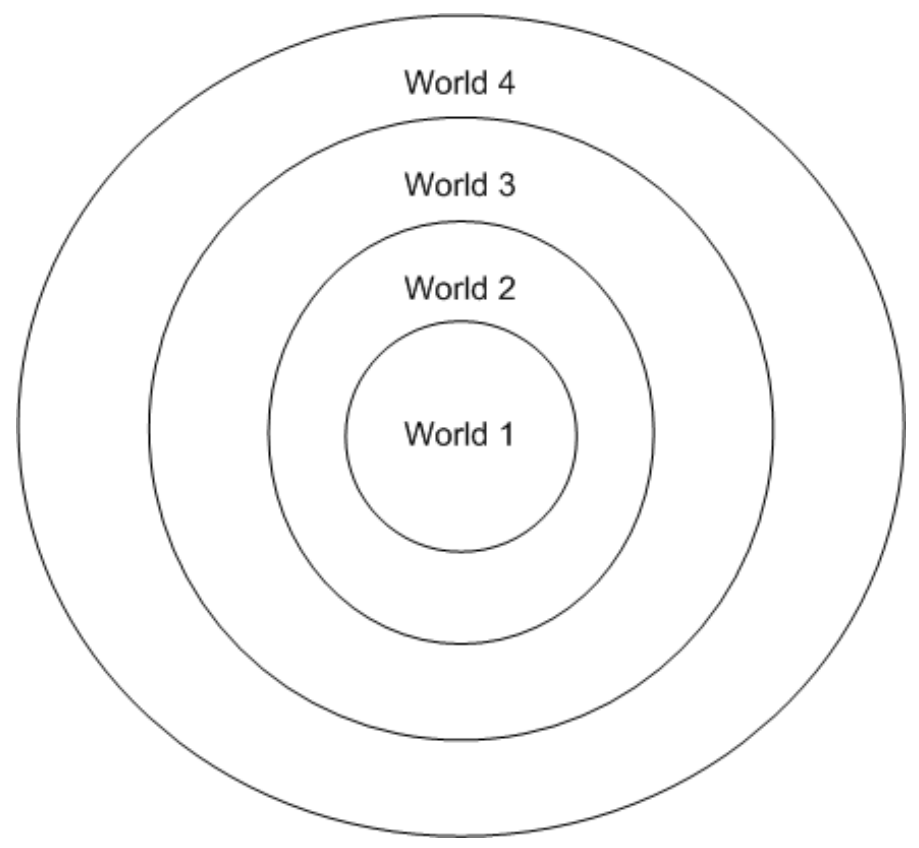

Figure 1 - The worlds we live in. based on (Atkin, 1997).

Everyone has associated four worlds:

- The first world is the world that is instilled in us;

- The second world is the world that the individual knows through direct experience;

- The third world is the world that the individual knows but never has had any experience with in a direct manner;

- The fourth and final world is the world of possibilities: the individual never heard or even have imagined its existence.

If you look at the pyramid of learning, we can see the natural environments, which are the most productive for learning: 


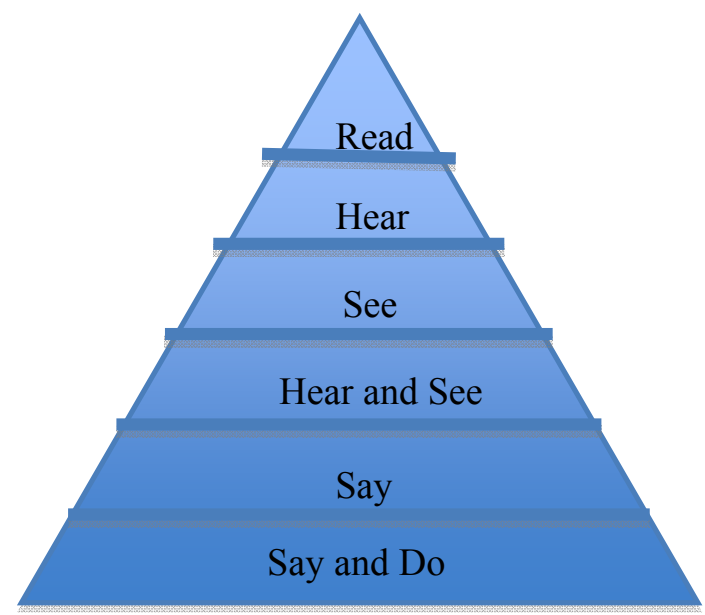

Figure 2 - The Learning pyramid based on NTL Institute for Applied Behavioral Science, 300 N. Lee Street, Suite 300, Alexandria, VA 22314

As we can see from Figure 2, reading, which is on top of the pyramid, achieves an average retention of learning of $5 \%$. On the opposite side is what is said and what is done, which reaches an average retention of learning of $90 \%$. This means that most of the things that a person learns are the things we say and do. Although we can say that reading is excellent, it is the smallest contribution for learning. The learning pyramid place the principal role to the interaction with other and, at least, with the world.

Before the traditional teaching in the classroom, collaborative environments were used for education among young people. Teams consisted of family members, as they were passing their knowledge to each other. The problem with this type of education was that the results were not always the same, ranging from family to family (as their environment could vary a lot both in knowledge and learning conditions). Because of this, it was necessary to create learning environments in classrooms, where there was a qualified teacher. This is not a natural environment of education, but an efficient way to teach (Webb, 2000).

There are several ways of learning in natural environments, such as a set of friends discussing a particular subject through the traditional modes of communication (coffee shops, meeting rooms, meetings at a friend's house, etc.), or a set of friends discussion a particular subject through the use of the new technologies (MSN, e-mail, forums, among many other services) (Webb, 2000).

We all have different interests. We want others to have interest in our interests and others wanted us to have interest in their interests. Often, due to social aspects, we try to share the same interests leaving the other side (Webb, 2000) - it is also a rather competitive attention environment.

Classroom students have to be interested in the interests of the teacher and the teacher has little interest in the interests of students. This is against the philosophy of how humans learn; if a student does not have interest in the interests of the teacher, students are considered a failure (Webb, 2000). Does this means that students do not learn?

In today's education it is almost a mandatory option for students to do a traditional test, whether it is done by computer or on paper (Webb, 2000).

\section{Collaborative Environments}

Collaborative learning is an act that results in a coordinated process of building and solving a particular problem (Roschelle \& Teasley, 1995). 
The act of learning is a fundamental cognitive process for personal and social development of humans during their existence (Andreas, Alexander, \& Matthias, 2005).

Collaborative learning provides an environment that can animate and enrich the learning process. The participation of various people in a collaborative environment permits the creation of an educational system more realistic in a particular social context, thereby increasing the effectiveness of the system. This type of environment helps to sustain the interest of the student, providing an habitat more natural for learning purposes (Kumar, 1996).

To have learning in a collaborative environment, you need to follow these characteristics (Landsberger, 2008; Salomon, 1992):

- Develop and share a common goal;

- Contribute to the understanding of the problem;

- Work, respond and understand the issues of other members;

- Responsibilities for all elements of the group;

- Dependency between group members so that everyone understands that the group's success depends on everyone;

Garrison, Anderson, and Archer (2001) report that, through the collaborative environment, participants gain a deeper learning, a shared understanding, and develop a critical thinking and enhance the retention of long-term learning.

The collaborative environments contain behaviors that improve learning. These environments contribute in a positive way for both situations where the participants are physically or through technology where they are communicating with each others (Curtis \& Lawson, 2001).

Dillenbourg (1999) defines collaborative learning as a situation where two or more people try to learn something in common and together. Each element of this definition can be interpreted in several ways:

- "Two or more persons" may be interpreted as a pair of people, a small group ( 3 to 5 persons), one class (20 to 30 people), community (a hundred or a thousand people) or a company ( one hundred thousand people), etc.

- "Learn something" can be interpreted as an accompaniment to a course, a given lecture of a discipline, solving a problem, etc.

- "Together" can be interpreted as different forms of interaction: face-to-face or through the new technologies of information and communication.

A group of people can never reach a perfect consensus of all of life, they need only to reach a reasonable consensus in order to continue the job they are doing (Clark \& Brennan, 1991).

Members participating in a collaborative environment aim to learn what was proposed and maintain a relationship between the group members (Roschelle, Rosas, \& Nussbaum, 2005).

The use of information activities has been considered crucial to the success of collaborative activities (Liu, Tao, \& Nee, 2008).

Currently, we see daily information activities, since we go to the Internet and we see appealing symbols about some new news, the publicity that we receive in our homes on promotion of a product, from receiving in our mobile phone SMS to inform us of new promotions, etc. Due to the competitive society that we live in, it is crucial that there are such information activities, so that our society can survive. 
The same is true in education, that is, if there is a greater volume of information activities the greater is the students' attention. If students have information about what is happening in a particular subject the greater is the interest of students, as demonstrated by Liu et al. (2008).

It is necessary that the group members are aware what each is doing, so that the collaboration between them can succeed (Gutwin, Greenberg, \& Roseman, 1996).

In a collaborative environment is necessary to have social awareness of other members, this is, if they are reachable or not, if they are well prepared or not, if they can be disturbed, just to name few situations. This social knowledge is essential because we can act according to their situation; for example, if a participant is sick maybe we should save the discussion for another day (Tollmar, Sandor, \& Schmer, 1996).

Information services have been developed in collaborative environments, in order to monitor and notify members of the group if any work has been done during the group work (Jang, Steinfield, \& Pfaff, 2000; Prinz \& Gross, 2001). Jang, et al. (2000) developed a system, the TeamScope, allowing them to notify group members through email and Java applets when any activity was done.

We can reach the conclusion that such research might prove that the groups have a great advantage to use mechanisms to notify the other elements of new activities made within the working group.

Since the notion of cooperation is inherent in collaborative learning, research can also be applied to collaborative learning environments. Both the cooperative and collaborative learning are built around the idea of socially constructed knowledge (Gouveia, 2001).

The two terms (cooperative learning and collaborative) are therefore often used synonymously, and there seems to exist a considerable ambiguity among them (Johnson \& Johnson, 1996). Sometimes the collaborative and cooperative environments can be interpreted in the same way, but these two types of environments have different characteristics.

Dillenbourg and Schneider (1995) make a distinction between cooperative and collaborative learning. They indicate that cooperative learning is a protocol in which, at the beginning, the initial task is subdivided into subtasks, so that the various participants are able to develop them independently. Collaborative learning describes situations where two or more subjects are built synchronously and interactively in order to reach a common solution to a problem (Dillenbourg \& Schneider, 1995).

Cooperative learning generally leaves the authority structures unchanged. The end is defined in the beginning by an instructor, who also describes the means by which the objective will be achieved and evaluate the whole process (Gouveia, 2001). Johnson and Johnson (1996) report that cooperative learning is based on the use of taught small groups, so that students can work together to maximize their own learning and that of others.

Collaborative learning is relatively cooperative, but it takes all participants a step forward, involving participants in a self-reflective process that often generates a series of issues of "meaning" and "power" and that forces them to confront issues that are implicit in any process of learning in the classroom, but are rarely explicitly defined and treated (Gouveia, 2001).

One of the major aspects that affect communication within a classroom is authority. The authority is the power that is given to a certain person, which may affect certain views, thoughts, and behaviors. Within a conventional classroom, the authority is the teacher. This means that students have a passive attitude in which they expect what they have to know to be given by the teacher. This type of behavior leads to monotony within a classroom (Hubscher-Younger \& Narayanan, 2003). 
Teachers should create learning environments that help students learn as effectively as possible. Given this scenario, we should not focus on teachers but on how students learn (Barr \& Tagg, 1995).

Learning is an act in which students will acquire knowledge, where students in collaboration with their peers and teachers build stable interpretations of their world (Sharples, 2005).

People learn together with peers and teachers, they learn as they compete and collaborate, they learn by example, they learn by doing and also correcting the concepts that were learned in previous cognitive activities (Laouris \& Eteokleous, 2005).

Nowadays universities are not only limited to the transfer of knowledge to students but are also concerned with social aspects. The ability to work in groups to communicate and collaborate is beneficial to purchase any kind of knowledge as well as an almost prerequisite for employability (Berger, Mohr, Nosekabel, \& Schafer, 2003).

\section{The Next Generation of Learning}

\section{Technology Environments}

Imagine that we are living in a time where cars could not go faster than $25 \mathrm{~km} / \mathrm{h}$, where letters were only written on paper, and where computers were only used for writing text. How could one live in this global economy and in this century? If you can not work with obsolete tools and services when it comes to survival, how can mainly text base appliancies continue to support an educational system that ignores the new research on learning and continues to "educate" using mainly outdated tools? (Caine \& Caine, 2007).

New technologies have created new spaces of knowledge. Now, besides the school, also the company and place of residence have become places of education and learning. The number of people in their homes using the Internet to increase their knowledge is increasing. The combination of a personal atmosphere, together with the ability to manage their time and what to learn, makes the use of courses of e-learning increase.

There is already a strong use of computers which makes them seen as a learning tool. The computer can still be understood, not as one common tool, but a tool for collaborative learning (and sometimes also cooperative). It allows communication and collaboration in common activities, providing also an excellent aid in the coordination and organization of activities. Computers and networks do not need to conform to many requirements, as long as they can be linked to Internet and to the school or organization they belong. Within such organization some support is needed to provide learners with the set of available courses.

"The learning of concepts, when taken in the broadest sense, is a personal act, everyday and informal" (Duarte \& Silva, 1995). The learning was and is developed in schools, where learners study the best way this could be developed. It is also in schools that those who are responsible, through education, can influence their students to assimilate the material taught (Duarte \& Silva, 1995).

For a long time, it was felt that teaching was primarily the transmission of knowledge content, the training of the memory, and the installation of the values of society in students. It was felt that learning was to acquire knowledge through a process of attention, memorization, and reproduction of it, which is an individual task, homogeneous, that would be standardized (Duarte \& Silva, 1995).

This type of learning, based on the "content dumping" on the student, was considered, supporting the idea of learning as knowledge construction. 
"The integration of computer in education is now a reality impossible to ignore and that we must understand." (Duarte \& Silva, 1995).

Thus, the use of computers in teaching fits the constructive approach to learning. Although the computer is not a technology designed for the education system, its characteristics of interaction and the system of choice for dealing with information makes it a very useful and promising tool (Duarte \& Silva, 1995).

The teaching method using the computer is an added value; it is certainly very appealing to students and more motivating, stimulating them to interact with different situations and depictions of real life, forcing the student to think creatively and independently about new subjects and materials.

Information technologies are rapidly changing the way we live. Computers, calculators, and other technologies for processing information help our brains to create knowledge from information. Until recently they were being used, in the majority of cases, for repetitive tasks (accounts, write, and print) and to perform these tasks in more rapidly and with a minimum of errors. Since the evolution of computers, they are already capable of being used for tasks far more complex than in the past. These tasks have a direct implication on how to create a learning environment (Cleveland, 1996):

- Access to unlimited information: computers allow users to access a vast amount of information;

- Interactive teaching: computers may be designated for interactive learning environments that allow students to learn at their own pace;

- Multimedia: since the advent of CD-ROM, this enables us to integrate teaching with voice, video, text, graphics and music;

- Simulation: The computers allow students to simulate different kind of experiences. These allow the exploitation of various kinds of experiences without students being limited to physical environments;

- Virtual Reality: Allows users to create experiences in an environment in three dimensions;

- Distance learning: The technology allows students to learn at any point in time in any place, without having to be in a particular geographical place;

- New connections: Computer networks allow students to connect with each other in order to share common knowledge among them.

If you go back to the past, we can see that the book was one of the most important technologies of the time. The invention of this technology was so important that it is still being used in schools, homes, libraries, etc. This has been used for centuries and will still be used in the future. If you think about this technology, we can ask ourselves about the success of this and how the success of the book can be applied to new technologies such as computer. If we look at the book we can conclude that this is intuitive, simple, and transparent, that is, when we use it we do not think about the technology itself but in its content (Boytchev, 2005).

These should be the principles that should be taken into account when we think about the use of new technologies. The use of new technologies can enhance learning or they may make it more difficult. As a result, the success of a technology is determined by its use and especially how it is introduced and managed (Boytchev, 2005).

When using the technology for education we should use it in a fair and moderate way. We must not overuse it, because it may lead to cases where the users are so addicted to the technology that 
they cannot release it or we just lose the main purpose of the process of using the supporting technology. In the opposite way, for users that are disconnected from the technology, they may never benefit from its advantages, as they do not get enough interaction to understand its processes (Buchan, 2008).

The main advantages that contribute to technology as an asset to the school environment are (Boytchev, 2005):

- The technology is attractive: You can not think of using a particular technology if it is not attractive. The attractiveness of technology is achieved by the mode of operation, and its appearance;

- The technology is available: A particular technology has no value to society if it is not used. The technology should not be locked or hidden from the users;

- Technology is addictive: This is an ambiguous feature of technology. This feature reflects the effort that users are making in order to learn to use the technology.

Educational technologies can be considered simply as a smaller set of information and communication technologies. However, what we do with those technologies is relevant; it is the way we use them and how we are encouraged to use this set of technologies, which makes the difference. Technologies for education are a key part of a learning environment (Buchan, 2008).

\section{Collaborative Technology Environments}

The advancement of new technologies has brought democracy to education. People today can spread knowledge more easily, compared with decade of the 60 s, mainly due to the emergence of the Internet (Liu \& Kao, 2007).

The use of new technologies leads us increasingly to a student-centered model (Bricall, 2004). This model is essential to have an intensive communication among students and between students and teachers. The forums are one of the key components for this type of communication. Its popularity is due to the fact that they are available 24 hours, 7 days a week, allowing users to operate them anytime and anywhere (Bermejo, 2005).

The advancement of the new technologies, today, has facilitated collaborative learning among the people, through synchronous and asynchronous mechanisms, allowing through them, greater ease of learning (Liu \& Kao, 2007).

The advancement of new technologies has facilitated the interaction between the groups. The network of computers - computer and networks - came to facilitate and promote discussion between groups (Stahl, 2002).

The teaching of online groups, also known as collaborative learning supported by computers (CSCL - Computer Supported Collaborative Learning), if implemented properly, could become an ideal environment where interaction between students predominate in the teaching process (Roberts \& McInnerney, 2007).

Members participating in a collaborative environment aim to learn what was proposed and maintain a relationship between the group members (Roschelle et al., 2005)

Although this is a better way to promote interaction between groups, there is a set of problems, so this strategy does not fit all the teaching.

Roberts and McInnerney (2007) mentioned a small set of the most common problems in a collaborative learning supported by computer:

- Lack of student motivation to work in groups; 
- The selection of groups;

- Lack of contextualization of the students in the context of the work group that they will perform;

- The parasitic attitude of the student;

- Inequality of knowledge among group members;

- The drop off of the members of the group;

- Evaluation of individual group members.

Ganeva, referenced by Hew and Cheung (2003), states that in an online asynchronous discussion messages sent by participants are stored for a long period of time, and people don't need to be attached simultaneously to participate in the forum.

An online forum has a set of desirable characteristics, including (Groeling, 1999):

- Gain on accessibility and opportunity for interaction;

- Removal of social barriers;

- Increase in time to "think" about the answers.

There are several studies whose research has focused on online forums. Hew (Hew \& Cheung, 2008) conducted a study to examine techniques used by tutors in order to attract the attention of students in discussion forums.

Rau, Gao, and $\mathrm{Wu},(2008)$ evaluated the motivation, pressure, and performance of teaching using communications: SMS, email and online forums.

Since the emergence of the Internet, it has been exploited in order to promote collaborative learning among students. A fact to consider is that not always we have access to the Internet, reducing the efficiency of computer-assisted collaborative learning. As a result the alternative use of SMS can improve this type of education because mobile phones are very common these days - the majority of young people and adults has one (Liu et al., 2008).

A major concern in today's schools is the students' motivation. One of the techniques used to handle this concern was the use of emails and discussion forums in order to promote group discussion. However we must take into consideration that the motivation issue is rather more complex and requires much more than the use of a particular strategy based on popular technology. But technology can help; Fussell et al. (1998) concluded that coordination between the group members improves group dynamics with the use of emails, so that they can communicate with each other.

\section{Mobile Technology Environments}

Mobile devices improve the dynamics of class, to the extent that students can bring them to the classroom and take advantage of them (Liu \& Kao, 2007).

The m-learning changes the paradigm of teacher-centered education to education at first hand at the right time and for a lifetime (Good, 2006). The main goal of m-learning is to increase the ability of students to learn at distance.

The use of mobile technologies in education will bring impacts on student motivation, collaboration among students, and on their mobility (Laouris \& Eteokleous, 2005).

Computers are becoming increasingly indispensable in our lives today; because of this, the market has increasingly invested in this reality. Ten years ago a mobile device served only to send 
text messages and for calling. Today these mobile devices let us do almost everything a computer does, in addition to telephone and sending text messages.

With the advancement of mobile technologies, the use of a computer is no longer restricted to a computer lab, a classroom, or an office and can be transported anywhere and anytime (Arman, Kori, Felix, Keith, \& Kellogg, 2001).

A collaborative learning supported by mobile computers overcomes the problems encountered in classroom collaborative learning (Zurita \& Nussbaum, 2004). This collaborative learning supported by mobile computers is called mCSCL (mobile Computer supported Collaborative Learning).

Barker, Krull, and Mallinson (2005) say that mobile devices enable groups of students to distribute, aggregate. and share information easily, resulting in a more successful collaboration.

There are several authors that refer to mobile technology as a technology that facilitates collaborative interactions (Cortez et al., 2004; Regan, Kori, Mark, Scott, \& James, 2001; Stead, 2005).

The specific mobile technologies that support collaborative learning have been introduced by Berger for Mohr, for Nösekabel, and Schäfer (2003), using a PDA with support for Wireless Application Protocol (WAP). Another example, with a Palm, is proposed by Cochrane (2005).

The specific implementation of collaborative learning in a mobile environment was considered by Frohberg (2004) and Burke, Colter, Little, and Riehl (2005); they reported statistics for these implementations. Personal Digital Assistants (PDAs), along with Palm and PocketPC devices, allow applications to connect to e-mail, instant messaging, RSS, forums, blogs, PDA, however these devices seems to be adopted as a tool for mobile learning excellence (Cochrane, 2005).

Although the Internet brings to the student a new concept of learning, mobile technologies seem to be in possession of any student today. Students can use mobile devices to do all kinds of tasks which they used to do with pen and paper, such as writing papers, taking notes in class and presentations (Houser \& Thornton, 2004) .

The massive use of mobile phones introduced a new style of communication between users, especially young ones. SMS, can be considered the application of elite of mobile technologies (Mitchell, Kadirire, \& Heppell, 2002). It can be used as a new form of communication in education (Bollen, Eimler, \& Ulrich Hoppe, 2004) by its own characteristics of providing mobility and an unique relation between the device, its number and the individual itself. The mobile phone is also one of the most used communication device to contact with friends and family (Divitini, Haugalokken, \& Norevik, 2002), so why not to take advantage of it to enhance learning.

Bollen et al. (2004) integrate a mobile device into a PC, allowing students to send SMS on various topics that may be discussed after the event in a classroom using a White Board.

\section{The Study}

\section{Objectives}

In order to evaluate the use of mobile devices in higher education and also to evaluate the perception and potential of mobile applications in collaborative environments, two experiments were performed involving students of higher education. The main objective of this study is to validate the perception and potential of the use of mobile applications for collaborative environments. The study also wants to research the potential of use of these devices in higher education. 


\section{Data Collection}

This study had two distinct phases. The first phase involves students in higher education with ages over 18 years old. The number of participants in this study was eighty-three who responded to a survey about their experience with mobile devices and collaborative environments.

The second phase involves students in higher education, with ages between 16 and 24 years. The number of participants was one hundred and eighty respondents who answered a survey about their perception of the use of mobile applications for collaborative environments.

Before initiating the study, we carried out a test with five students to analyze the effectiveness of the investigation. This test concluded that some questions were subjective, and, as a result, we had to reformulate some questions of the survey.

\section{Application}

The first survey was passed through the Internet with the help of "Google Docs". Data collection was performed in the last two weeks of March in the year 2009.

The instrument used was a survey consisting of several sessions, to check at the end of the study the perception of the student's use of applications on mobile devices. The data were obtained from eighty-three valid questionnaires collected from students with ages greater than 18 years.

The second survey was passed through the Internet with the help of "EncuestaFacil". Data collection was performed during the months of June and July of 2009.

The instrument used was a survey consisting of several sessions, in order to study which is the student's perception of the use of mobile applications on collaborative environments. The data were obtained from eighty valid questionnaires collected from students with ages between 16 and 24 years.

\section{Data Analysis}

This first study was composed of $79.52 \%$ males, of which $83.13 \%$ were older than 20 years.

The most frequently used mobile devices are mobile phones (74) and laptops (69), and such students spend more time with mobile phones and laptops (38 and 57, respectively).

Regarding the use of the e-mail on mobile devices, 22 do not use this application (26.51\%) and 13 indicate that they use it $(15.66 \%)$. As regards to the future use of the e-mail on mobile devices and the 22 respondents who do not use the e-mail on mobile devices, 9 of them indicate to aspire to use this application (40.91\%). Regarding the usefulness of the e-mail on mobile devices, 58 $(69.88 \%)$ totally agree with the usefulness of this application.

In regards to the use of Internet access in a mobile device, 16 do not use it (19.28\%) and 37 indicate that they use it $(44.58 \%)$. As regards to the future use of Internet access on mobile devices and the 16 respondents who do not use Internet access on mobile devices, 10 of them indicated to aspire to use this application (62.50\%). Regarding the usefulness of Internet access on mobile devices, 66 are fully agreed on the usefulness of this application $(79.52 \%)$.

As regards to the use of file transport on mobile device, 8 do not use it (9.64\%) and 46 indicate that they use it $(55.42 \%)$. As regards to the future use of file transport on mobile devices and the 8 respondents who did not use it, 4 of them indicate to aspire the use of this application $(50 \%)$. Regarding the usefulness of the file transport on mobile devices, 57 are fully agreed of the usefulness of this application $(68.67 \%)$.

Regarding the use of the camera in a mobile device, 9 do not use it (10.84\%) and 28 indicate that the use it $(33.73 \%)$. As regards to the future use of the camera on mobile devices and the 9 re- 
spondents who did not use it, 5 of them indicate to aspire the use of this application (55.56\%). Regarding the usefulness of the camera on mobile devices, 31 are fully agreed on the usefulness of this application (37.35\%).

Of the 83 respondents, $48.19 \%$ send more than 30 messages per day. It appears that a majority of respondents have used discussion forums in learning environments $(73.49 \%)$

Of those who have used discussion forums in learning environments, it appears that, mostly, the students think that discussion forums are useful for learning $(96.72 \%)$.

Of those who think that forums are helpful for learning, 32.84\% report that they are useful to answer questions, while $44.07 \%$ say that they are essential for knowledge sharing (Figure 3 ).

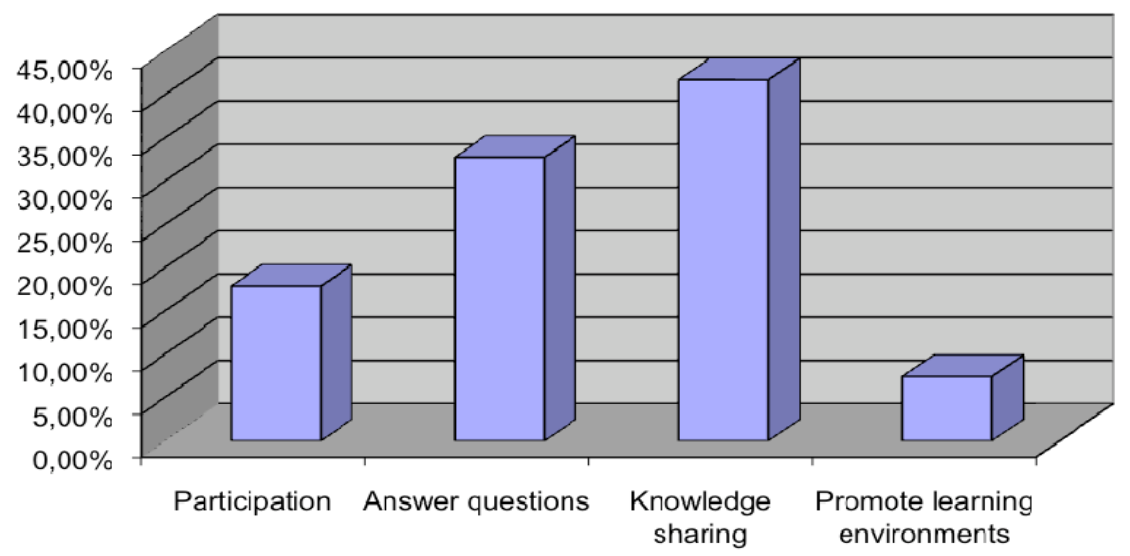

Figure 3 - Factors for why forums are helpful for learning

The second study was composed of $65 \%$ males and $71.25 \%$ had ages between 16 and 24 .

All the students know Hi5 (100\%) and their majority uses it (79\%), however, very few would pay to use it $(5 \%)$.

Mostly, the inquired students know Facebook and the majority does not use it (83\% and $71 \%$, respectively).

Regarding the use of Orkut, $54 \%$ know it and $88 \%$ do not use it. Mostly, the inquired are familiar with MySpace and the majority does not use it (83\% and $71 \%$, respectively) and very few would be willing to pay to use it $(8 \%)$.

Mostly, the inquired know Google Groups and the majority does not use it (58\% and 70\%, respectively) and very few would be willing to pay to use (10\%).

Mostly, the inquired are familiar with Yahoo Groups and the majority does not use it $(56 \%$ and $75 \%$, respectively). All inquired know SMS and most use it (100\% and $95 \%$, respectively).

As regards to MSN, it appears that, mostly, the inquired know MSN and that most use it (98\% and $93 \%$, respectively).

Half of the inquired know Twitter and very few use it (50\% and $11 \%$, respectively). The majority knows Wiki services and uses it some (66\% and 68\%, respectively) and most of the inquired will not be available to pay to use it.

As for the Blog, it appears that, mostly, the inquired know it and use it (91\% and 59\%, respectively).

The majority of students inquired does not know Flikr and does not use it (65\% and $93 \%)$ and they do not know Twain (94\%), Digg (80\%) and del.icio.us (88\%). 
With regard to Youtube, it appears that the majority knows and uses Youtube (96\% and $95 \%$ respectively) and that most are not willing to pay to use it (91\%).

In accordance with the following data, it appears that twenty-five of the respondents mainly use the mobile device to call, twenty-one to access the Internet intensively, and forty-eight use these devices to send SMS's intensively. Concerning access to MSN, e-mail, and the use of games, the majority of respondents does not use mobile devices for such purposes (Figura 4).

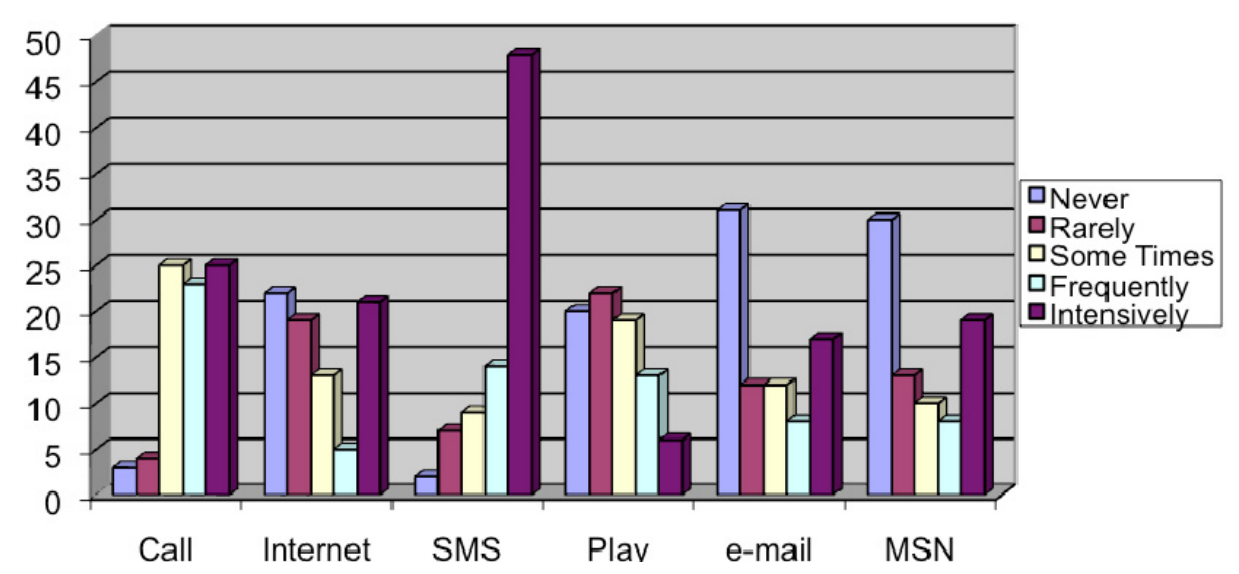

Figure 4 - Utility of the mobile devices

\section{Conclusions}

Based on data collected from the surveys, we can conclude the following:

Regarding the use of e-mail on mobile devices, most do not use this application, but those who do not use it want to use it in the future. As to its usefulness, most agree with their advantages.

The majority uses the Internet on a mobile device, but those who do not use it want to use it in the future. As to its usefulness, most agree with their advantages. Regarding the use of file transport on a mobile device the majority uses it, but those who do not use it want to use it in the future. As to its usefulness, most agree with their advantages. The majority uses the camera on a mobile device, but those who do not use it want to use it in the future. As to its usefulness, most agree with their advantages.

The reason that students do not use some of these applications, previously mentioned, may be related to the fact that these applications consume a lot of battery. For example, in the case of WiFi on a mobile device, access to e-mail reduces battery time. Usability can also be another factor that is related to lack of use of some mobile applications.

Regarding the sending of SMSs, nearly half of respondents indicates that they send more than 30 SMSs every day. It appears that a majority of respondents have used discussion forums in learning environments, and those who have used it find it useful for learning and still think forums are useful to clarify doubts and to share knowledge.

As regards to the use of mobile applications in collaborative environments, the most familiar applications are Hi5, Facebook, MySpace, Google Groups, Yahoo Groups, SMS, MSN, Twitter, Wiki, Blogs and YouTube. For Flikr, Twain, Digg and del.icio.us, the respondents did not know these applications.

For the use of mobile applications in collaborative environments, respondents reported only applications as Hi5, SMS, MSN, wiki, blogs and YouTube. 
For the inclination of the respondents to pay for the use of the applications listed in this study, the only one was SMS.

For the type of use that is made from a mobile device, it appears that twenty-five of the respondents mainly use the device to call, twenty-one to access the Internet intensely, and forty-eight used it to send SMSs. Concerning access to MSN, e-mail, and the use of games, the majority of respondents do not use mobile devices for these purposes.

Thus, it is possible to define the profile of the respondents; they are people who know a lot of mobile applications in collaborative environments, use only the most common and popular, and are not willing, for most of them, to pay to use them. They are also people who use common applications on mobile devices, and those who do not use it want to use them in the future. The majority of respondents have used forums, linking this to good learning.

We also can conclude that the majority of the students do not intend to pay for the use of any application besides SMS. As for the use of the Internet on mobile devices, we can think that this is used when connected to the WIFI. Hi5, Facebook, MySpace, Google Groups, Yahoo Groups, SMS, MSN, Twitter, Wiki, Blogs and YouTube can be used by the majority of the students because these are free applications, otherwise, their popularity wouldn't be for sure the same.

\section{Future Work}

A high number of people all around the world use mobile devices. Due to the advance of new technologies, and their size, users can carry them anywhere, anytime, can connect to a wide range of information anywhere they go.

Despite the widespread use of mobile devices today, there is a lack of reference to identify the advantages and disadvantages of m-learning as collaborative environment, that is, we can not see $\mathrm{m}$-learning as an extension of e-learning but as a break in the process of teaching and learning.

Given this, it is important to study the influence of m-learning in collaborative learning environments.

The expected results of this study are:

- Contribute to a better understanding of the benefits of collaborative environments in the m-learning in the face of e-learning;

- Improve the quality of interaction of actors in the work group.

\section{References}

Andreas, H., Alexander, N., \& Matthias, M. (2005). Lifelong-learning support by m-learning: Example scenarios. Association of Computing Machinery ACM eLearn Magazine, 5.

Arman, D., Kori, I., Felix, L., Keith, S., \& Kellogg, B. (2001). GeneyTM: Designing a collaborative activity for the palmTM handheld computer. Paper presented at the CHI 2001, Seattle.

Atkin, J. (1997). Enhancing learning with information and communication technology: Promises, pitfalls and practicalities. Seminar Series No. 70. Incorporated Association of Registered Teachers of Victoria: Melbourne.

Barker, A., Krull, G., \& Mallinson, B. (2005). A proposed theoretical model for M-Learning adoption in developing. Paper presented at the Proceedings of mLearn 2005.

Barr, R. B., \& Tagg, J. (1995). From teaching to learning: A new paradigm for undergraduate education. Change Magazine, 13-25. 
Berger, S., Mohr, R., Nosekabel, H., \& Schafer, K. J. (2003). Mobile collaboration tool for university education. Paper presented at the WETICE 2003, Linz.

Bermejo, S. (2005). Cooperative electronic learning in virtual laboratories through forums. Education, IEEE Transactions on Education, 48(1), 140-149.

Bollen, L., Eimler, S., \& Ulrich Hoppe, H. (2004). SMS-based discussions - technology enhanced collaboration for a literature course. Paper presented at the Wireless and Mobile Technologies in Education, 2004. Proceedings of the 2nd IEEE International Workshop on Wireless and Mobile Technologies in Education.

Boytchev, P. (2005). Technology enhanced natural learning. Paper presented at the Technology Enhanced Learning Workshop.

Bricall, J. M. (2004). University report 2000. Spanish Ministry of Education.

Buchan, J. (2008). Tools for survival in a changing educational technology environment. ASCILITE 2008, 100-109.

Caine, G., \& Caine, R. (2007). Natural learning: The basis for raising and sustaining high standards of real world performance. Position paper: Natural Learning Research Insitute.

Chiarello, L., Shelden, M., Rapport, M., Barnett, J., Cicirello, N., \& Kennedy, E. (2001). Early intervention services: Natural learning environments. Alexandria, VA: Section on Pediatrics, American Physical Therapy Association.

Clark, H. H., \& Brennan, S. (1991). Grounding in communication. Perspectives on Socially Shared Cognition, 127-149.

Cleveland, J. (1996). The changing nature of learning. On Purpose Associates. Retrieved from http://www.nupolis.com/public/item/222077

Cochrane, T. $(2005,2005)$. Mobilising learning: A primer for utilising wireless palm devices to facilitate a collaborative learning environment. Paper presented at ASCILITE 2005.

Cortez, C., Nussbaum, M., Santelices, R., Rodriguez, P., Zurita, G., Correa, M., et al. (2004). Teaching science with Mobile Computer Supported Collaborative Learning (MCSCL). 2nd IEEE Internacional WorkShop on Wireless and Mobile Technologies in Education, 67-74.

Curtis, D. D., \& Lawson, M. J. (2001). Exploring collaborative online learning. Journal for Asynchronous Learning Networks, 5(1), 21-34.

Dillenbourg, P., \& Schneider, D. (1995). Collaborative learning and the internet. Retrieved 1-12-2009, from http://tecfa.unige.ch/tecfa/research/CMC/colla/iccai95 1.html

Divitini, M., Haugalokken, O. K., \& Norevik, P. A. (2002). Improving communication through mobile technologies: which possibilities? Paper presented at the Wireless and Mobile Technologies in Education, 2002. Proceedings. IEEE International Workshop on Wireless and Mobile Technologies in Education

Duarte, M. C. \& Silva, J. L. C. (1995). O Computador no Ensino/Aprendizagem das ciências: um nova forma de utilização. Revista Portuguesa de educação.

Fussell, S. R., Kraut, R. E., Lerch, F. J., Scherlis, W. L. , McNally, M. M., \& Cadiz, J. J. (1998). Coordination, overload and team performance: effects of team communication strategies. Paper presented at the Proceedings of the 1998 ACM conference on Computer supported cooperative work.

Garrison, D. R., Anderson, T., \& Archer, W. (2001). Critical thinking and computer conferencing: a model and tool to access cognitive presence. American Journal of Distance Education, 15(1), 7-23.

Good, R. (2006). Learning on the move: MLearning is next. Retrieved 2007/07/07, from http://www.masternewmedia.org/news/2006/01/17/learning_on the move_mlearning.htm

Gouveia, L. M. B. (2001). A visualisation design for sharing knowledge. Lancaster University, Lancaster. 
Groeling, T. (1999). Virtual discussion: Web-based discussion forums in political science. Department of Communication Studies/Speech, UCLA.

Gutwin, C., Greenberg, S., \& Roseman, M. (1996). Supporting awareness of others in groupware. Paper presented at the Conference Companion on Human Factors in Computing Systems: Common Ground.

Hew, K. F., \& Cheung, W. S. (2003). An exploratory study on the use of asynchronous online discussion in hypermedia design. e-Journal of Instructional Science and Technology (e-Jist).

Hew, K. F., \& Cheung, W. S. (2008). Attracting student participation in asynchronous online discussions: A case study of peer facilitation. Computers \& Education, 51(3), 1111-1124.

Houser, C., \& Thornton, P. (2004). Japanese college students' typing speed on mobile devices. Proceedings of the 2nd IEEE International Workshop on Wireless and Mobile Technologies in Education (WMTE'04).

Hubscher-Younger, T., \& Narayanan, N. H. (2003). Authority and convergence in collaborative learning. Computer Education, 41(4), 313-334.

Jang, C. Y., Steinfield, C., \& Pfaff, C. (2000). Supporting awareness among virtual teams in a web-based collaborative system: The teamSCOPE system. SIGGROUP Bulletin, 21(3), 28-34.

Johnson, D. W., \& Johnson, R. T. (1996). Cooperation and the use of technology. In Handbook of research for educational communications and technology (pp. 1017-1044). New York: Simon \& Schuster Macmillan.

Kumar, V. S. (1996). Computer-supported collaborative learning: Issues for research. Retrieved 1-122009, from http://www.uib.no/People/sinia/CSCL.

Landsberger, J. (2008). Cooperative \& collaborative learning. Retrieved 3-10-2007, from http://www.studygs.net/cooplearn.htm

Laouris, Y., \& Eteokleous, N. (2005). We need an educationally relevant definition of mobile learning. Paper presented at the Proceedings of mLearn 2005.

Liu, C. C., \& Kao, L. C. (2007). Do handheld devices facilitate face-to-face collaboration? Handheld devices with large shared display groupware to facilitate group interactions. Journal of Computer Assisted Learning, 23(4), 285-299.

Liu, C. C., Tao, S. Y., \& Nee, J. N. (2008). Bridging the gap between students and computers: Supporting activity awareness for network collaborative learning with GSM network. Behaviour \& Information Technology, 27(2), 127 - 137.

Mitchell, A., Kadirire, J., \& Heppell, S. (2002). Technology watch research report. Angalia: UltraLab.

Okyere, E. W., Rothkopf, E. M., \& Kim, C. (1993). Innovative use of computers as tools in technology education at the College of Staten Island. Proceedings of the Frontiers in Education Conference, 1993. Twenty-Third Annual Conference. 'Engineering Education: Renewing America's Technology'.

Prinz, W., \& Gross, T. (2001). Ubiquitous awareness of cooperative activities in a theatre of work. In A. Bode \& W. Karl (Eds.), Fachtagung Arbeitsplatzcomputer: Pervasive Ubiquitous Computing (pp. 135144). APC.

Rau, P. L. P., Gao, Q., \& Wu, L. M. (2008). Using mobile communication technology in high school education: Motivation, pressure, and learning performance. Computers \& Education, 50(1), 1-22.

Regan, L. M., Kori, M. I., Mark, B., Scott, R. K., \& James, A. L. (2001). Supporting children's collaboration across handheld computers. Paper presented at the Conference on Human Factors in Computing Systems, Seattle, Washington.

Roberts, T. S., \& McInnerney, J. M. (2007). Seven problems of online group learning (and their solutions). Educational Technology \& Society, 10(4), 257-268. 
Roschelle, J., Rosas, R., \& Nussbaum, M. (2005). Towards a design framework for mobile computersupported collaborative learning. CSCL 2005: Computer Supported Collaborative Learning 2005: The Next 10 Years, Proceedings, 520-524.

Roschelle, J., \& Teasley, S. D. (1995). The construction of shared knowledge in collaborative problem solving. Paper presented at the Computer Supported Collaborative Learning.

Salomon, G. (1992). What does the design of effective CSCL require and how do we study its effects? SIGCUE Outlook, 21(3), 62-68.

Sharples, M. (2005, 2005). Learning as conversation: Transforming education in the mobile age. Proceedings of Conference on Seeing, Understanding, Learning in the Mobile Age.

Stahl, G. (2002). Groupware goes to school. Proceedings of the 8th International Workshop on Groupware: Design, Implementation and Use.

Stead, G. (2005). Moving mobile into the mainstream. Paper presented at the Mlearn 2005: 4th World conference on mLearning.

Tollmar, K., Sandor, O., \& Schmer, A. (1996). Supporting social awareness @ work design and experience. Proceedings of the 1996 ACM Conference on Computer Supported Cooperative Work.

Webb, R. L. (2000). Natural learning environments:tools for student responsibility. Retrieved 1-12-2008, from http://home.att.net/ youth.motivation/natural_learning.ht

Zurita, G., \& Nussbaum, M. 1. (2004). Computer supported collaborative learning using wirelessly interconnected handheld computers. Computers \& Education, 42(3), 289-314.

\section{Biographies}

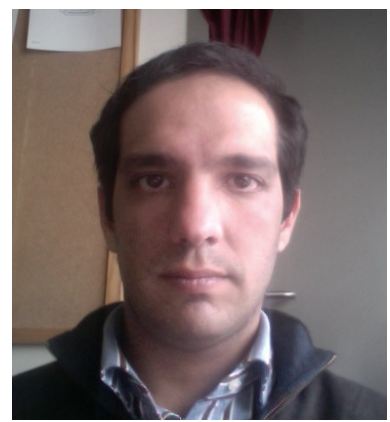

Steven Lopes Abrantes is a teacher at Polytechnic Institute of Viseu. He is a Phd student at the University of Fernando Pessoa, Porto. He holds a Master degree in Information Management (University of Aveiro, 2007) and a Bachelors degree on Computer Science (University of Coimbra, 2004). His interests are in the application of computer technologies in education, in particular, the use of mobile technologies in distance learning.

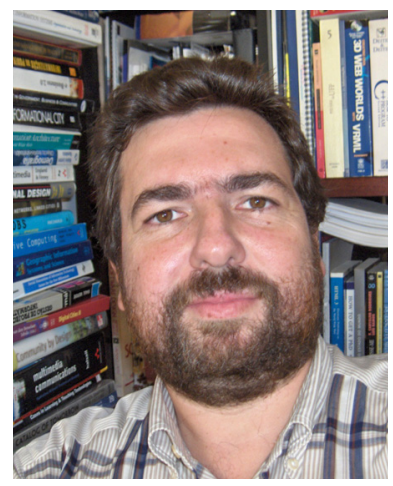

Luis Borges Gouveia is an Associate Professor at University Fernando Pessoa. He holds a PhD in Computer Science (University of Lancaster, 2002) and a Masters degree in Electronic and Computers Engineering (University of Oporto, 1995). His interests are within the impact of information society and digital use both in education and business.

Luis has a Web homepage at http://homepage.ufp.pt/ lmbg 